\title{
Eating Buckwheat Cookies Is Associated with the Reduction in Serum Levels of Myeloperoxidase and Cholesterol: A Double Blind Crossover Study in Day-Care Centre Staffs
}

\author{
Gunilla Wieslander, ${ }^{1}$ Nina Fabjan, ${ }^{2}$ Maja Vogrinčič, ${ }^{2}$ Ivan Kreft,${ }^{2}$ Christer Janson, ${ }^{3}$ \\ Ulrike Spetz-Nyström, ${ }^{3}$ Blanka Vombergar, ${ }^{4}$ Christer Tagesson, ${ }^{5}$ Per Leanderson ${ }^{5}$ \\ and Dan Norbäck ${ }^{1}$ \\ ${ }^{1}$ Department of Medical Science, Occupational and Environmental Medicine, Uppsala University, University \\ Hospital, Uppsala, Sweden \\ ${ }^{2}$ Biotechnical Faculty, University of Ljubljana, Ljubljana, Slovenia \\ ${ }^{3}$ Department of Medical Science, Respiratory Medicine and Allergology, University Hospital, Uppsala University, \\ Uppsala, Sweden \\ ${ }^{4}$ Education Center Piramida, Vocational College, Maribor, Slovenia \\ ${ }^{5}$ Department of Clinical and Experimental Medicine, Occupational and Environmental Medicine, Linköping \\ University, Linköping, Sweden
}

\begin{abstract}
Buckwheat food is a good source of antioxidants, e.g. rutin, and other beneficial substances. Here we investigated the effects of the intake of common buckwheat (low rutin content) and tartary buckwheat cookies (high rutin content) on selected clinical markers. A double blind crossover study was performed among female day-care centre staffs $(N=62)$ from five day-care centres. Participants were randomly divided into two groups. The first group initially consumed four common buckwheat cookies per day (16.5 $\mathrm{mg}$ rutin equivalents/day) for two weeks, while the second group consumed four tartary buckwheat cookies per day (359.7 mg rutin equivalents/day). Then the groups switched their type of cookies and consumed them for another two weeks. We monitored selected clinical markers related to cardiovascular disease and lower airway inflammation, lung function, and subjective breathing difficulties in the staffs. Intake of tartary buckwheat cookies reduced the serum level of myeloperoxidase (MPO) by a factor $0.84(p=0.02)$. When grouping the two types of buckwheat cookies together, there was a reduction of total serum cholesterol $(p<0.001)$ and HDL-cholesterol $(p<0.001)$ during the study period, with improved lung vital capacity $(p<$ 0.001 ). The degree of reduction in total and HDL cholesterol levels was similar in staffs with low and high body mass index (cut off 25). In conclusion, intake of tartary buckwheat cookies with high level of the antioxidant rutin may reduce levels of MPO, an indicator of inflammation. Moreover, intake of both types of buckwheat cookies may lower cholesterol levels.
\end{abstract}

Keywords: antioxidant experiment; buckwheat; cholesterol; inflammation; lung function

Tohoku J. Exp. Med., 2011, 225 (2), 123-130. (C) 2011 Tohoku University Medical Press

There is an increased interest in the beneficial health effects of dietary antioxidants intake, because they can help to prevent different types of diseases. Buckwheat is a good source of antioxidants, biologically high-valued amino acids (Krkoškova and Mrazova 2005; Jiang et al. 2007), dietary fiber (Bonafaccia et al. 2003), and minerals such as zinc, copper and manganese (Ikeda and Yamashita 1994). In Shanxi province, China, both common (Fagopyrum esculentum) and tartary (Fagopyrum tataricum) buckwheats are used to improve the health of patients with diabetes and cardiovascular diseases (Wieslander et al. 2000). A previous experimental buckwheat study concluded that intake of common buckwheat leaf tea could prevent further development of leg edema (Ihme et al. 1996), and a study by He et al. (1995) showed a cholesterol-lowering effect of buckwheat. However, there are very few studies on the health effects of buckwheat, especially buckwheat products in humans. Japanese studies indicate that some of the beneficial effects of buckwheat may be related to the low digestibility of buckwheat (Ikeda and Yamashita 1994). Skrabanja et al. (2001) reported beneficial effects of starch in common buckwheat with respect to insulin response. Buckwheat is also a good source of rutin (Fabjan et al. 2003), which has many potentially health-beneficial effects

Received June 1, 2011; revision accepted for publication August 26, 2011. doi: 10.1620/tjem.225.123

Correspondence: Gunilla Wieslander, Department of Medical Science, Occupational and Environmental Medicine, Uppsala University,

University Hospital, Uppsala, 75185 Sweden.

e-mail: gunilla.wieslander@medsci.uu.se 
according to in vitro and animal studies.

In vitro tests have shown that rutin (quercetin glycoside) may inhibit low-density lipoprotein (LDL) oxidation (Milde et al. 2004; Jiang et al. 2007) and high-density lipoprotein (HDL) oxidation (Meng et al. 2004), and that quercetin may be an effective inhibitor of human myeloperoxidase activity (Pincemail et al. 1988). In addition, secretory phospholipase $\mathrm{A}_{2}$ ( $\mathrm{SPLA}_{2}$ group IIA), which is both a mediator and a marker of cardiovascular disease (Chait et al. 2005), is inhibited by flavonoids such as quercetin (Lindahl and Tagesson 1993) and rutin (Lindahl and Tagesson 1997). Rutin and other polyphenols were able to attenuate endotoxin-induced airway contraction in isolated rat lungs (Nosratabadi et al. 2003). A study on rodents has shown an anti-allergic effect of buckwheat grain extract, due to the inhibition of histamine release and cytokine gene expression in the mast cells (Kim et al. 2003). Webster et al. (1996) showed a protective role of rutin in DNA damage and repair enzymes in rats. Park et al. (2002) made a study of effects of rutin and tannic acid supplements on cholesterol metabolism in rats. They observed a lowering effect on plasma and hepatic cholesterol. This could be due to reduced myeloperoxidase (MPO) activity (Loria et al. 2008). Bioactive compounds in buckwheat sprouts have also lowered the LDL level in hamsters (Lin et al. 2008), which suggests that rutin could lower the risk of arteriosclerosis. According to Kwon et al. (2005), rutin has an antiinflammatory effect and influence on the cytokine patterns (reducing IL-1 $\beta$, IL-6, IL-10, IL-13 and TNF- $\alpha$ ) in mice.

Although there is evidence for many possible beneficial effects of rutin and other polyphenols, there is a lack of experimental dietary studies on health effects in humans as well as on the beneficial properties of buckwheat and specially buckwheat products. The main aim of this study was to evaluate the possible effects of consuming tartary buckwheat, which has high content of rutin, on selected biomarkers related to cardiovascular disease (CVD) and lower airway inflammation, lung function and dyspnoea. Here consumption of common buckwheat, which has low content of rutin, was used as control. In addition, we investigated if there was an effect of eating buckwheat on the biomarkers, lung function and dyspnoea over the study period, irrespectively of type of buckwheat.

\section{Subjects, Materials and Methods}

The main hypothesis was that an increased intake of rutin from tartary buckwheat cookies could have an effect on levels of total cholesterol, HDL cholesterol, secretory phospholipase $\mathrm{A}_{2}$ ( $\mathrm{sPLA}_{2}$ group IIA), high sensitivity $\mathrm{C}$ reactive protein (HsCRP), eosinophilic cationic protein, MPO, nitric oxide (NO) in exhaled breath, lung function and dyspnoea. To isolate the effect of rutin, common buckwheat cookies were baked using the same recipe as for tartary buckwheat cookies. Common buckwheat contains less rutin than tartary buckwheat and can as such be used as a control. A double blind experimental crossover study was performed among staff working in five day-care centres in Uppsala. All staffs $(N=70)$ were invited and 62 choose to participate initially (90\%). All 62 participants fulfilled the study, but 3-4 persons each time could not participate in all tests for various reasons. The local government at Uppsala administered contact lists on leadership. The researchers informed all invited staffs at meetings and collected participants signed consent forms, followed later by investigations. Participants were randomly divided into two groups. One group, consisting of staffs from two of the day-care centres $(N=30)$, ate four tartary buckwheat (Fagopyrum tataricum) cookies (TBW) per day for two weeks. The content of rutin in daily dosage (4 cookies) was about $360 \mathrm{mg}$ rutin equivalents, measured by chemical analysis of cookies. The second group, participants from the other three day care centres $(N=32)$, was first given four common buckwheat (Fagopyrum esculentum) cookies (CBW) a day. The latter contained lower levels of rutin (17 mg rutin equivalents/daily dosage). After two weeks, the two groups switched their type of cookie ("crossover design") and the experiment continued directly for another two weeks.

All experiments have been performed in compliance with the relevant laws and institutional guidelines for this kind of studies in April 2005, and the study was performed May 2005. WHO regulation of clinical studies came in 2006. Informed consent was obtained from all the participants. The protocol of the study was approved by the Regional Ethical Committee of Uppsala University (2005/65).

\section{Recipe for the buckwheat cookies}

Buckwheat cookies were baked at the College of Food Technology, Maribor, Slovenia (Vombergar and Gostenčnik 2005). Two types of cookies were prepared from common and tartary buckwheat flour respectively, according to the following recipe. The dough consisted of $970 \mathrm{~g}$ buckwheat flour (tartary or common), $30 \mathrm{~g}$ cocoa powder, $400 \mathrm{~g}$ margarine, $400 \mathrm{~g}$ powdered sugar, $250 \mathrm{~g}$ (five) eggs, $10 \mathrm{~g}$ vanilla sugar, $10 \mathrm{~g}$ lemon skin, $1 \mathrm{~g}$ salt and $12 \mathrm{~g}$ of baking powder. Cocoa was used to hide the yellow color of TBW, and lemon skin and vanilla were used to cover the bitter taste of TBW. Cookies were baked for $12 \mathrm{~min}$ at $185^{\circ} \mathrm{C}$. The tartary buckwheat used was a domestic cultivar, grown and milled in Luxemburg and while the common buckwheat (cv. Siva) was grown and milled in Slovenia.

\section{Flavonoid extraction and HPLC analyses}

Buckwheat cookies were freeze-dried, pulverized and extracted with $80 \%$ methanol for $30 \mathrm{~min}$. Methanol extracts were centrifuged (10 min, 10,000 g, $4^{\circ} \mathrm{C}$, Sigma $3 \mathrm{~K} 30$ ) and filtered through Millipore, Durapore (22 $\mu \mathrm{m}$ GVPP) prior to analyses, which was performed in triplicate in three independent samples.

HPLC separation of flavonoids was performed using a Waters 2690 Separations Module connected to a 996 Photodiode Array Detector (Waters corporation, Milford, Massachusetts) and equipped with a Millenium32 Chromatography Manager (Waters corporation, Milford, Massachusetts). Methanol extracts were injected at ambient temperature into a Symmetry RP C-18 $(4.6 \mathrm{~mm} \times 250 \mathrm{~mm}, 5 \mu \mathrm{m}$, Waters S.A.S., France) injector. The mobile phases were: methanol (A), acetonitrile (B), bi-distilled water (C), with flow rate of $1 \mathrm{~mL}$ / min. Gradient elution was applied from 44\% (A), 11 (B), and 45 (C) as follows: 0-10 $\min 47$ (A), 11(B), 42 (C); 10-20 min 64 (A), 16 (B), $20(C)$. Acquisition was set at $350 \mathrm{~nm}$ (spectral acquisition in the range $210-400 \mathrm{~nm}$ ). Identification and quantification of flavonoids in buckwheat cookies was made by comparing their chromatographic data with those of standard flavonoids. 


\section{Medical investigation}

Initially all participants answered a general questionnaire on asthma, allergies, and demographic data. Each volunteer was tested at the beginning of the study to detect common allergens through a skin prick test. Each subject participated in the clinical examination three times during the study (at the beginning, end of week 2 and end of week 4). They ate one type of cookie for the first two weeks, and the other type during weeks 3-4.

Information on current symptoms of breathlessness (dyspnoea) was obtained from a questionnaire. Answers were given on a 100$\mathrm{mm}$ visual analogue rating scale (VAS-scale) based on the Borg-scale (Nihlen et al. 1998). The scale has endpoints graded from "no perceived symptoms at all" (0), to "unbearable symptoms" (100). In addition, it has fixed points with verbal expressions at certain points of the line, 7 means hardly any, 22 a few, 50 many, 78 a lot and 93 a great many perceived symptoms.

Venous blood was collected in EDTA tubes for analysis of total cholesterol, HDL cholesterol, secretory phospholipase $\mathrm{A}_{2}$ (sPLA $_{2}$ group IIA), and HsCRP. In addition, venous blood was collected in 5 $\mathrm{mL}$ SST tubes for analysis of eosinophilic cationic protein (ECP) and MPO in serum. The concentrations of ECP and MPO were measured by means of a double antibody radioimmunoassay method (Pharmacia Diagnostics AB, Uppsala). NO in exhaled breath (FENO) was analysed by NIOX-mino (Aerocrine, Stockholm, Sweden). Lung function was studied by dynamic spirometry [vital capacity (VC), forced vital capacity (FVC), peak expiratory flow (PEF), and forced expiratory flow were measured for one second (FEV1) (SPIRA). All the tests were carried out in a standardized way with the same well-calibrated spirometer by a trained nurse. The measurements were performed three times on each subject, and the highest values were noted. A test was considered adequate when the deviation between the two best tests was less than $5 \%$. The results were expressed as a percentage of normal values based on standardization to age, sex, height, smoking habits and body mass using a reference material from Uppsala (Hedenstrom 1986).

\section{Statistics}

Since the inflammatory biomarkers and the ratings of dyspnoea were not normally distributed, the non-parametric Mann-Whitney $U$-test was applied to test differences in changes of these variables comparing the two groups with different intake sequence. Difference between weeks, irrespectively of type of buckwheat consumption, was analyzed by the Wilcoxon matched pairs signed ranks test. Cardiovascular biomarkers and lung function were approximately normally distributed, and were analyzed using Student's $t$-test, and paired $t$-test, respectively. In addition, generalized least squares, a multivariate model, were used to analyze clinical marker effects that were significantly related to intake of rutin (tartary buckwheat) in the bivariate analysis. In all analysis, a 2 -tailed p-value below 0.05 was considered statistically significant.

\section{Results}

Flavonoids in buckwheat cookies

Analysis of flavonoids content was done using HPLC and levels of rutin and quercetin are shown in Table 1 . Since quercetin is rapidly metabolised to rutin, the daily intake was expressed as rutin equivalents, by adding the levels of quercetin and rutin, but adjusting for the different molecular weights of the two compounds by multiplying the quercetin level by the ratio rutin molecular mass/quercetin molecular mass. Daily intake of four TBW (approximately $62 \mathrm{~g}$ ) corresponded to $359.7 \mathrm{mg}$ of rutin equivalents. Daily intake of four CBW (approximately $61 \mathrm{~g}$ ) corresponded to $16.5 \mathrm{mg}$ of rutin equivalents. Average daily intake of rutin was about $5.1 \mathrm{mg} / \mathrm{kg}$ body weight for TBW and about $0.2 \mathrm{mg} / \mathrm{kg}$ for $\mathrm{CBW}$.

\section{Clinical test}

Baseline data were measured at the beginning of the study. Mean age was 46 years (s.D. $=10)$, mean height was $165 \mathrm{~cm}$ (s.D. $=6$ ), mean weight was $70 \mathrm{~kg}($ S.D. $=13)$ and mean body mass index (BMI) was $25.5 \mathrm{~kg} / \mathrm{m}^{2}$ (s.D. $=4.1$ ). Fourteen percent were obese $\left(\mathrm{BMI}>30 \mathrm{~kg} / \mathrm{m}^{2}\right), 31 \%$ were overweighed (BMI $25-30 \mathrm{~kg} / \mathrm{m}^{2}$ ) and $53 \%$ had a normal BMI $\left(20-25 \mathrm{~kg} / \mathrm{m}^{2}\right)$. All participants were female with only few smokers $(n=4)$. They had a normal lung function. Descriptive data at baseline, including allergies are given in Table 2. When comparing the outcome variables between

Table 1. Flavonoid contents in tartary buckwheat cookies (TBW) and common buckwheat cookies (CBW), daily intake 4 cookies per person during 2 weeks, respectively .

\begin{tabular}{lcc}
\hline \multicolumn{1}{c}{ Flavonoid content } & TBW & CBW \\
\hline Flavonoid concentration & & \\
Rutin in mg per kg DW & 2,530 & 270 \\
Quercetin in mg per kg DW & 1,620 & 0 (**B.t.1.) \\
Content of rutin + quercetin calculated as rutin equivalents* in mg per kg DW & 5,802 & 270 \\
Cookie content & & 4.1 \\
Rutin equivalents* per cookie (mg) & 89.9 & 16.5 \\
Daily intake (4 cookies*) of rutin equivalents in mg & 359.7 & \\
\hline
\end{tabular}

DW, dry weight

*rutin equivalents are calculated by ratio: rutin/quercetin molecular mass.

Daily intake of TBW (4 cookies $)=62 \mathrm{~g}$, Daily intake of CBW $(4$ cookies $)=61 \mathrm{~g}$

$* *$ B.t.l. $=$ below threshold limit. 
Table 2. Descriptive data at baseline for the participants in the study $(N=62)$.

\begin{tabular}{lc}
\hline \multicolumn{1}{c}{ Type of parameter } & Baseline data \\
\hline Female & $100 \%$ \\
Current smoker & $6 \%$ \\
Current cold (last week) & $5 \%$ \\
Pollen allergy & $16 \%$ \\
Cat allergy & $11 \%$ \\
Dog allergy & $6 \%$ \\
Horse allergy & $2 \%$ \\
House dust mite allergy & $2 \%$ \\
Mould allergy & $0 \%$ \\
Atopy & $18 \%$ \\
Lung function data: & Mean values \\
FVC (L) & $3.25(109 \%$ of predicted $)$ \\
FEV1 (L/s) & $2.88(104 \%$ of predicted $)$ \\
FEV1 (\%) & $82.2(103 \%$ of predicted $)$ \\
PEF (L/s) & $7.02(106 \%$ of predicted $)$ \\
FENO (ppb) & 17 \\
\hline
\end{tabular}

a at least one positive skin prick test to common allergens (pollen, pet or moulds)

FVC, forced vital capacity; FEV1, forced expiratory volume in 1 second; FEV\%, FEV1/FVC in \%; PEF, peak expiratory flow; FENO, fenotype nitrogenoxide. the two intervention groups, mean values at baseline were mostly similar. In the group eating CBW first $(N=32)$, the mean baseline levels of sPLA2, total cholesterol, HDL cholesterol, serum MPO, serum ECP, FeNO, HsCRP, FVC. $\mathrm{FEV} \%, \mathrm{FEV} 1 \%, \mathrm{PEF} \%$ and rating of dyspnoea were 7.06 $\mathrm{ng} / \mathrm{ml}, 153.8 \mathrm{mmol} / \mathrm{L}, 14.8 \mathrm{mmol} / \mathrm{L}, 1.83 \mu \mathrm{g} / \mathrm{mL}, 5.02 \mu \mathrm{g} /$ $\mathrm{mL}, 15 \mathrm{ppb}, 1.38 \mathrm{mg} / \mathrm{L}, 109 \%, 104 \%, 103 \%$ and $15.8 \%$. In the group eating TBW first $(N=30)$, the mean baseline levels of sPLA2, total cholesterol, HDL cholesterol, serum MPO, serum ECP, FeNO, HsCRP, FVC\%. FEV\%, FEV1\%, $\mathrm{PEF} \%$ and rating of dyspnoea were $6.51 \mathrm{ng} / \mathrm{ml}, 191.6$ $\mathrm{mmol} / \mathrm{L}, 16.02 \mathrm{mmol} / \mathrm{L}, 2.36 \mu \mathrm{g} / \mathrm{mL}, 5.58 \mu \mathrm{g} / \mathrm{mL}, 20 \mathrm{ppb}$, $1.33 \mathrm{mg} / \mathrm{L}, 108 \%, 104 \%, 109 \%$ and $13.3 \%$. Thus, the levels of total cholesterol, serum MPO, serum ECP, FeNO, HsCRP and $\mathrm{PEF} \%$ were numerically higher in the group eating TBW first, while the levels of sPLA2 and rating of dyspnoea were numerically lower, and mean levels of other variables were the same. No statistical testing was performed for these differences. At baseline, six persons had elevated levels of MPO according to the reference value from the laboratory $(>271 \mathrm{mg} / \mathrm{l})$. None had any known disease but all six had overweight.

Initially, the changes of clinical marker effects from baseline to week 2 and from baseline to week 4 were analyzed irrespectively of the type of buckwheat cookies consumed (Table 3). There was a significant reduction of total-cholesterol and HDL-cholesterol after 4 weeks, and a significant improvement of lung function as seen for FVC

Table 3. The mean values ( \pm S.D.) of clinical markers for the baseline and the pooled up values after uptake of the buckwheat cookies after two and four weeks (any type) $(N=62)$.

\begin{tabular}{|c|c|c|c|}
\hline Clinical parameter & Baseline Pre-exposure & After 2 weeks & After 4 weeks \\
\hline \multicolumn{4}{|l|}{ Cardiovascular markers $^{\mathrm{a}}$} \\
\hline $\mathrm{sPLA}_{2}(\mathrm{ng} / \mathrm{mL})$ & $6.8 \pm 3.7$ & $7.1 \pm 4.0$ & $6.3 \pm 3.1$ \\
\hline Total cholesterol (mmol/L) & $5.31 \pm 0.95$ & $5.21 \pm 1.12$ & $4.59 \pm 1.28 * * *$ \\
\hline HDL cholesterol (mmol/L) & $1.36 \pm 0.36$ & $1.51 \pm 1.48$ & $1.15 \pm 0.35^{* * *}$ \\
\hline \multicolumn{4}{|l|}{ Inflammation markers ${ }^{\mathrm{b}}$} \\
\hline Serum MPO (mg/L) & $173 \pm 114$ & $181 \pm 122$ & $160 \pm 93$ \\
\hline Serum ECP (mg/L) & $15.4 \pm 12.2$ & $14.7 \pm 10.9$ & $15.3 \pm 10.8$ \\
\hline FeNO (ppb) & $18 \pm 10$ & $19 \pm 14$ & $20 \pm 14$ \\
\hline $\mathrm{HsCRP}(\mathrm{mg} / \mathrm{L})$ & $2.10 \pm 3.46$ & $2.05 \pm 2.89$ & $1.85 \pm 2.22$ \\
\hline \multicolumn{4}{|c|}{ Lung function markers ${ }^{\mathrm{a}}$ and dyspnoea ${ }^{\mathrm{b}}$} \\
\hline FVC (\% predicted) & $109 \pm 16$ & $110 \pm 18$ & $114 \pm 17 * * *$ \\
\hline FEV1 (\% predicted) & $104 \pm 13$ & $104 \pm 15$ & $104 \pm 15$ \\
\hline PEF (\% predicted) & $107 \pm 20$ & $108 \pm 20$ & $109 \pm 20$ \\
\hline Difficulty in breathing & $15 \pm 19$ & $16 \pm 20$ & $15 \pm 21$ \\
\hline
\end{tabular}

$* * * P<0.001$

a $P$-value for change from baseline values by Student's $t$-test for paired comparisons.

${ }^{\mathrm{b}} P$-value for change from baseline values by Wilcoxon pair test.

sPLA $_{2}$, group IIA secretory phospholipase $\mathrm{A}_{2}$; HDL, high density lipoprotein (cholesterol); FeNO, fenotype nitrogenoxide; HsCRP, high sensitive C reactive protein; MPO, myeloperoxidase; ECP, eosinophilic cation protein; FVC, forced vital capacity; FEV1, forced expiratory volume in 1 second; FEV, \% FEV1/FVC; PEF, peak expiratory flow. 
Table 4. Comparison of the change in clinical marker values in the two groups.

\begin{tabular}{|c|c|c|c|c|c|c|}
\hline \multirow{2}{*}{ Clinical parameter } & \multicolumn{3}{|c|}{$\begin{array}{c}\text { Net change } \\
\text { baseline to week } 2\end{array}$} & \multicolumn{3}{|c|}{$\begin{array}{c}\text { Net change } \\
\text { week } 2 \text { to week } 4\end{array}$} \\
\hline & $\begin{array}{c}\text { Group I } \\
\text { TBW } \\
(N=30)\end{array}$ & $\begin{array}{c}\text { Group II } \\
\text { CBW } \\
(N=32)\end{array}$ & $\mathrm{DIF}^{\mathrm{c}}$ & $\begin{array}{c}\text { Group I } \\
\text { CBW } \\
(N=30)\end{array}$ & $\begin{array}{c}\text { Group II } \\
\text { TBW } \\
(N=32)\end{array}$ & $\mathrm{DIF}^{\mathrm{c}}$ \\
\hline \multicolumn{7}{|l|}{ Cardiovascular markers $^{\mathrm{a}}$} \\
\hline $\mathrm{sPLA}_{2}(\mathrm{ng} / \mathrm{mL})$ & 0.51 & 0.23 & 0.28 & -1.03 & -0.60 & 0.43 \\
\hline Total cholesterol (mmol/L) & -0.17 & -0.15 & 0.02 & -0.65 & -0.52 & 0.13 \\
\hline HDL cholesterol (mmol/L) & 0.29 & -0.01 & 0.30 & -0.52 & -0.18 & 0.34 \\
\hline \multicolumn{7}{|l|}{ Inflammation markers ${ }^{\mathrm{b}}$} \\
\hline Serum MPO $(\mu \mathrm{g} / \mathrm{mL})$ & 8.6 & 11.4 & 0.71 & 8.3 & $-55.4 *$ & $63.7 *$ \\
\hline Serum ECP $(\mu \mathrm{g} / \mathrm{mL})$ & -0.89 & -0.18 & 0.28 & 1.88 & -1.05 & 2.93 \\
\hline FeNO (ppb) & 1.10 & 1.50 & 0.40 & -1.3 & 0.4 & 1.7 \\
\hline $\operatorname{HsCRP}(\mathrm{mg} / \mathrm{L})$ & 0.45 & -0.37 & 0.82 & -0.32 & -0.27 & 0.05 \\
\hline \multicolumn{7}{|c|}{ Lung function markers ${ }^{\mathrm{a}}$ and dyspnoea ${ }^{\mathrm{b}}$} \\
\hline FVC (\% predicted $)$ & -0.7 & 3.8 & 4.5 & -0.4 & 2.7 & 3.1 \\
\hline $\mathrm{FEV}_{1}(\%$ predicted $)$ & -1.2 & 1.2 & 2.4 & -2.9 & -0.6 & 2.3 \\
\hline PEF (\% predicted) & 1.3 & 1.3 & 0 & -2.3 & 0.6 & 2.9 \\
\hline Difficulty in breathing & +1 & 0 & 1 & 1 & -2 & 3 \\
\hline
\end{tabular}

$* P=0.02$

TBW, tartary buckwheat cookies; CBW, common buckwheat cookies.

SPLA $_{2}$, group IIA secretory phospholipase $\mathrm{A}_{2}$; HDL, high density lipoprotein (cholesterol); FeNO, fenotype nitrogenoxide; HsCRP, high sensitive $\mathrm{C}$ reactive protein; MPO, myeloperoxidase; ECP, eosinophilic cation protein; FVC, forced vital capacity; FEV1, forced expiratory volume in 1 second; FEV, \% FEV1/FVC; PEF, peak expiratory flow.

Group I ate TBW first for two weeks and then changed to CBW for two weeks.

Group II ate CBW first for two weeks and then changed to TBW for two weeks.

a $P$-value calculated for difference in change between the two groups by Student's $t$-test

${ }^{\mathrm{b}} P$-value calculated for difference in changes between the two groups by Mann-Whitney $U$-test

${ }^{c}$ Differences in clinical marker changes between Group I and II from baseline to week 2, or week 2 to 4 . Statistically significant difference is marked with *.

by $5 \%(p<0.001)$, but no significant change in $\mathrm{FEV}_{1}$, other clinical marker effects or dyspnoea was seen overtime. When stratifying the material with respect to high BMI $(>25)$ or low BMI $(\leq 25)$, the differences between levels at baseline and after 4 weeks were significant in both groups. In those with high BMI, the mean total cholesterol level was 5.23 (s.D. $=0.83$ ) at baseline and 4.60 (s.D. $=1.38$ ) after 4 weeks $(p=0.02)$, and mean HDL cholesterol was 1.38 (s.D. $=0.37$ ) at baseline and 1.16 (s.D. $=0.35$ ) after 4 weeks $(p=0.008)$. In those with low BMI, the mean total cholesterol level was 5.51 (S.D. $=1.03$ ) at baseline and 4.57 (S.D. $=1.21)$ after 4 weeks $(p<0.001)$, and mean HDL cholesterol was 1.37 (s.D. $=0.37$ ) at baseline and 1.14 (s.D. $=$ $0.34)$ after four weeks $(p<0.001)$. This study did not analyze the triglycerides as all blood samples were taken at the workplace non-fasting and during normal work hours. LDLs were not analyzed, unfortunately. However this antihypercholesterolemic effect and the underlying mechanisms should be analyzed. Both types of buckwheat cookies had this effect.

When comparing changes of clinical marker effects and dyspnoea in relation to specific type of buckwheat cookies, we observed a statistically significant decrease of MPO levels in relation to consumption of TBW when comparing week 2 and week $4(p=0.02)$ (Table 4). There was no significant effect on other biomarkers or dyspnoea. The association between consumption of buckwheat cookies (treatment) and MPO was further analyzed with generalized least squares (GLs), including baseline, period and treatment group in the model and logarithmic values of serum MPO. In the GLs model, there was a significant decrease of serum MPO when eating TBW ( $p=0.02)$, with a $17 \%$ reduction of $\log$ serum MPO $(95 \%$ CI $-3 \%$ to $-31 \%)$. Taking anti-log data $\left(\mathrm{e}^{\mathrm{x}}\right)$, this corresponds to a 0.84 times lower level of serum MPO (95\% CI 0.73-0.97). Residual plots of predicted and independent variables and normal plot for the residuals were checked, and all were satisfactory.

\section{Discussion}

The study had a double blind crossover design using two types of buckwheat cookies, made out of common and 
tartary buckwheat with low and high content of rutin, respectively. Analysis of the cookies showed that the daily dosage of $\mathrm{CBW}$ (4 pieces) contained $17 \mathrm{mg}$ of rutin equivalents, while daily dosage (4 pieces) of TBW contained 360 mg of rutin equivalents. Knekt et al. (2002) have estimated the average daily intake of flavonoids $(24.2 \mathrm{mg})$ and quercetin, into which rutin is transformed $(3.3 \mathrm{mg})$ in Finnish food. This dosage was increased in both types of cookies with emphasis on TBW.

One limitation of the study was the short study period of only two weeks per type of buckwheat, which could have limited the possibility to study long-term effects. Quercetin is quickly transformed to rutin in the body, and the turnover of rutin is rapid (Graefe and Veit 2000). Since there was a 21 times higher level of rutin equivalents in the TBW, and intake of rutin equivalents from $\mathrm{CBW}$ was of the same order of magnitude as the average daily intake in a Nordic country, we considered the blinded cross-over design as a suitable study design to study the effect of rutin, which was the main aim. There was a slight increase of rutin intake when eating common buckwheat cookies but this increase was much less than the pronounced increased when consuming TBW. Another limitation is that there was no reference group, eating cookies without buckwheat flour (e.g. based on wheat). This limitation is especially important when studying effects of other compounds than rutin, common in both type of buckwheat. However, since the study period was short, we have no reason to believe that there was any considerable change of dietary habits that could have influenced the levels of cholesterol.

The levels of total cholesterol and HDL-cholesterol decreased significantly, when comparing baseline data with levels after four weeks, irrespectively of type of cookies consumed. The decrease was consistently significant, and of a similar magnitude, both in staff with normal weight $(\mathrm{BMI} \leq 25)$ and in those with overweight or obesity (BMI > 25). This consistency reduces the possibility that the decrease is due to other factors, such as dietary changes during the study period. The results can be interpreted as a cholesterol lowering effect of buckwheat, not related to the content of rutin. Lowering of total cholesterol can reduce the risk for cardiovascular disease. Unfortunately we could not get any data on LDL-cholesterol or triglycerides from our clinical laboratory. One mechanism could be that the cholesterol lowering effect is due to resistant starch present in buckwheat. Skrabanja et al. (2001) made a study on nutritional properties of starch in buckwheat products and they demonstrated that buckwheat and buckwheat products have a low glycemic index due to resistant starch. Liu et al. (2001) reported on cholesterol lowering effects of food with low glycemic index in humans. A previous study on the health effects of flavonoids on hypocholesterolemia in chicken fed with $20 \mathrm{mg}$ of rutin per day for 28 days concluded, that rutin reduced the levels of total cholesterol, HDL-cholesterol and LDL-cholesterol (Da Silva et al. 2001). The cholesterol-lowering effect of rutin was also observed in rats (Park et al. 2002). An in vitro study also concluded that rutin and flavonoid contents in buckwheat had a beneficial effect against lipid peroxidation (Jiang et al. 2007). Another explanation could be that there are other compounds in both types of buckwheat than rutin with a cholesterol lowering effect. Decreased levels of plasma cholesterol, and less gallstone formation in hamsters were observed with a buckwheat protein extract diet, from both common and tartary buckwheat, as compared to a casein or soy protein diet (Tomotake et al. 2000). Similar effects were seen in rats and mice (Tomotake et al. 2007). Consumption of buckwheat protein reduced plasma cholesterol in rats as reported by Kayashita et al. (1997). Lin et al. (2008) also observed a reduced effect of bioactive compounds in buckwheat sprouts on LDL-cholesterol in hamsters but did not see a change in HDL-cholesterol levels. Our findings, suggesting a lipid-lowering effect of buckwheat, irrespectively of the type, are in agreement with a previous study from China (He et al. 1995). However, they share the same weakness as our study, since they do not include a control group that did not eat buckwheat. He et al. (1995) also concluded that daily intake of 100 gram of buckwheat lowered total and LDL cholesterol levels in 850 Yi people of ethnic minority in China; however, they did not specify the kind of buckwheat consumed. Further research in humans is needed to confirm the observed cholesterol-lowering effect of buckwheat.

Our results suggest that increased intake of rutin with TBW may have an influence on reduction of serum MPO level. We found no previous studies in humans on effects of rutin on MPO levels. However, this effect of rutin on MPO is in agreement with a previous in-vitro study (Pincemail et al. 1988). Moreover, in one study in rats with experimentally induced refux esophagitis, treatment with rutin $(18.3 \mathrm{mg} / \mathrm{kg}$ body weight $)$ inhibited lipid peroxidation and reduced MPO levels in comparison to untreated controls (Shin et al. 2002). In another study in rats with gastric ulcers induced by $50 \%$ ethanol, lipid peroxidation was reduced by intake of rutin ( $200 \mathrm{mg} / \mathrm{kg}$ body weight), but no effect was seen on levels of MPO (La Casa et al. 2000). MPO is responsible for LDL oxidation, which can be inhibited by micromolar concentrations of flavonoids, including rutin, according to another in vitro study (Kostyuk et al. 2003). Since MPO is a marker of neutrophilic inflammation (Loria et al. 2008), rutin may have an anti-inflammatory function due to its ability to lower MPO levels. We observed an improvement in FVC after four weeks. That could also be due to training effect, since the participants might get used to the test. However, since the spirometry was done by a professionally trained nurse, the chance of training effect is less likely. No significant effects of rutin intake were observed for other inflammatory biomarkers (serum ECP, HsCRP, and FENO) or obstructive lung function parameters $\left(\mathrm{FEV}_{1}\right.$ and $\left.\mathrm{PEF}\right)$.

In conclusion, our study is a contribution to studies on the health effects of rutin and other components in buck- 
wheat. According to our results, consumption of buckwheat may have a beneficial effect on lowering cholesterol and reducing cardiovascular risks. In addition, consumption of tartary buckwheat, which has a high content of rutin, may have an anti-inflammatory effect with respect to neutrophilic inflammation. The present study is one of the first to deal with the health benefits of buckwheat products in humans. However, further experimental human studies on the health effects of buckwheat consumption are needed. We suggest longer study periods, as well as a study design that makes it possible to evaluate effects of compounds occurring in both types of buckwheat.

\section{Conflict of Interest}

The authors have no conflict of interest.

\section{References}

Bonafaccia, G., Marocchini, M. \& Kreft, I. (2003) Composition and technological properties of the flour and bran from common and tartary buckwheat. Food Chem., 80, 9-15.

Chait, A., Han, C.Y., Oram, J.F. \& Heinecke, J.W. (2005) The immune system and atherogenesis. Lipoprotein-associated inflammatory proteins: markers or mediators of cardiovascular disease? J. Lipid Res., 46, 389-403.

Da Silva, R.R., de Oliveira, T.T., Nagem, T.J., Pinto, A.S., Albino, L.F., Almeida, L.R., de Moraes, G.H. \& Pinto, J.G. (2001) Hypocholesterolemic effect of naringin, and rutin flavonoids. Arch. Latinoam. Nutr., 51, 258-264.

Fabjan, N., Rode, J., Košir, I.J., Wang, Z., Zhang, Z. \& Kreft, I. (2003) Tartary buckwheat (Fagopyrum tataricum Gaertn.) as a source of dietary rutin and quercetrin. J. Agric. Food Chem., 51, 6452-6455.

Graefe, E.U. and Veit, M. (2000) Urinary metabolites of flavonoids and hydroxycinnamic acids in humans after application of a crude extract from Equisetum arvense. Phytomedicine, 6, 239-246.

He, J., Klag, M.J., Whelton, P.K., Mo, J.P., Chen, J.Y., Qian, M.C., Mo, P.S. \& He, G.Q. (1995) Oats an buckwheat intakes and cardiovascular disease risk factors in an ethnic minority of China. Am. J. Clin. Nutr., 61, 366-372.

Hedenstrom, H. (1986) Selection of lung function tests and interpretation of their results. In: Acta Upsaliensis Almqvist \& Wiksell, Stockholm, Sweden, pp 1-29. Thesis.

Ihme, N., Kiesewetter, H., Jung, F., Hoffmann, K.H., Birk, A., Muller, A. \& Grutzner, K. (1996) Leg oedema protection from buckwheat herb tea in patients with chronic venous insufficiency: a single-centre, randomised, double blind, placebo-controlled clinical trial. Eur. J. Clin. Pharmacol., 40, 443-447.

Ikeda, S. \& Yamashita, Y. (1994) Buckwheat as a dietary source of zinc, copper and manganese. Fagopyrum, 14, 29-34.

Jiang, P., Burczynski, F., Campbell, C., Pierce, G., Austria, J.A. \& Briggs, C.J. (2007) Rutin and flavonoid contents in three buckwheat species Fagopyrum esculentum, F. tataricum, and $F$. homotropicum and their protective effects against lipid peroxidation. Food Res. Inter., 40, 356-364.

Kayashita, J., Shimaoka, I., Nakajoh, M., Yamazaki, M. \& Kato, N. (1997) Consumption of buckwheat protein lowers plasma cholesterol and raises fecal neutral sterols in cholesterol-fed rats because of its low digestibility. J. Nutr., 127, 1395-1400.

Kim, C.D., Lee, W.K., No, K.O., Park, S.K., Lee, M.H., Lim, S.R. \& Roh, S.S. (2003) Anti-allergic action of buckwheat (Fagopyrum esculentum Moench) grain extract. Int. Immunopharmacol., 3, 129-136.

Knekt, P., Kumpulainen, J., Järvinen, R., Rissanen, H., Heliövaara,
M., Reunanen, A., Hakulinen, T. \& Aromaa, A. (2002) Flavonoid intake and risk of chronic disease. Am. J. Clin. Nutr., 76, 560-568.

Kostyuk, V.A., Kraemer, T., Sies, H. \& Schewe, T. (2003) Myeloperoxidase/nitrite-mediated lipid peroxidation of low-density lipoprotein as modulated by flavonoids. FEBS Lett., 537, 146-150.

Krkoškova, B. \& Mrazova, Z. (2005) Prophylactic components of buckwheat. Food Res. Intern., 38, 561-568.

Kwon, K.N., Murakami, A., Tanaka, T. \& Ohigashi, H. (2005) Dietary rutin, but not its aglycone quercetin, ameliorates dextran sulphate sodium-induced experimental colitis in mice: attenuation of pro-inflammatory gene expression. Biochem. Pharmacol., 69, 395-406.

La Casa, C., Villegas, I., Alarcon de la Lastra, C., Motilva, V. \& Martin Calero, M.J. (2000) Evidence for protective and antioxidant properties of rutin, a natural flavone, against ethanol induced gastric lesions. J. Ethnopharmacology, 71, 45-53.

Lin, L.Y., Peng, C.C., Yang, Y.L. \& Peng, R.Y. (2008) Optimization of bioactive compounds in buckwheat sprouts and their effect on blood cholesterol in hamsters. J. Agric. Food Chem., 6, 1216-1223.

Lindahl, M. \& Tagesson, C. (1993) Selective inhibition of group II phospholipase $\mathrm{A}_{2}$ by quercetin. Inflammation, 17, 573-582.

Lindahl, M. \& Tagesson, C. (1997) Flavonoids as phospholipase $\mathrm{A}_{2}$ inhibitors: Importance of their structure for selective inhibition of group II phospholipase $\mathrm{A}_{2}$. Inflammation, 21, 347-356.

Liu, S., Manson, J.E., Stampfer, M.J., Holmes, M.D., Hu, F.B., Hankinson, S.E. \& Willett, W.C. (2001) Dietary glycemic load assessed by food frequency questionnaire in relation to plasma high-density-lipoprotein cholesterol and fasting plasma triacylglycerols. Am . J. Clin. Nutr., 73, 560-566.

Loria, V., Dato, I., Graziani, F. \& Biasucci, L. (2008) Myeloperoxidase: a new biomarker of inflammation in ischemic heart disease and acute coronary syndromes. Mediators Inflam., 1, $1-4$.

Meng, F., Liu, R., Bai, H., Liu, B.W., Liu, Y., Tang, C.W. \& Liu, B.W. (2004) Inhibitory effect of quercetin, rutin and puerarin on HDL oxidation induced by $\mathrm{Cu} 2+$. Sichuan Da Xue Xue Bao Yi Xue Ban, 32, 2058-2062. (in Chinese)

Milde, J., Elstner, E.F. \& Grassman, J. (2004) Synergistic inhibition of low-density lipoprotein oxidation by rutin, gammaterpinene, and ascorbic acid. Phytomedicine, 11, 105-113.

Nihlen, A., Walinder, R., Löf, A. \& Johanson, G. (1998) Experimental exposure to methyl tertiary-butyl ether II. Acute effects in humans. Toxicol. Appl. Pharmacol., 148, 281-287.

Nosratabadi, A.R., Ljungman, A.G., Lindahl, M., Welch, R., Pilon, A. \& Tagesson, C. (2003) Clara cell 10-kDA protein inhibits endotoxin-induced airway contraction in isolated perfused rat lungs. Exp. Lung. Res., 29, 455-473.

Park, S.Y., Bok, S.H. \& Jeon, S.M. (2002) Effect of rutin and tannic acid supplements on cholesterol metabolism in rats. Nutr. Res., 22, 83-95.

Pincemail, J., Deby, C., Thirion, A., de Bruyn-Dister, M. \& Goutier, R. (1988) Human myeloperoxidase activity is inhibited in vitro by quercetin. Comparison with three related compounds. Experientia, 15, 450-453.

Shin, Y.K., Sohn, U.D., Choi, M.S., Kum, C., Sim, S.S. \& Lee, M.Y. (2002) Effects of rutin and harmaline on rat reflux oesophagitis. Auton. Autacoid Pharmacol., 22, 47-55.

Skrabanja, V., Liljeberg, E.H.G., Kreft, I. \& Björck, I.M.E. (2001) Nutritional properties of starch in buckwheat products: studies in vitro and in vivo. J. Agric. Food Chem., 49, 490-496.

Tomotake, H., Shimaoka, I., Kayashita, J., Yokohama, F. \& Nakajoh, M.K. (2000) A buckwheat protein product suppresses formation of plasma cholesterol more strongly than soy protein isolate in hamsters. J. Nutr., 130, 1670-1674.

Tomotake, H., Yamamoto, N., Kitabayashi, H., Kawakami, A., Kayashita, J., Ohinata, H., Karasawa, H. \& Kato, N. (2007) 
Preparation of tartary buckwheat protein product and its improving effect on cholesterol metabolism in rats and mice fed cholesterol-enriched diet. J. Food Sci., 72, 528-533.

Vombergar, B. \& Gostenčnik, D. (2005) Priprava ajdovih keksov za prehranske poskuse - Production of buckwheat cookies for nutritional studies. Acta Agric. Slov., 85, 397-409.

Webster, R.P., Gawde, M.D. \& Bhattacharya, R.K. (1996) Protec- tive effect of rutin, a flavonol glycoside, on the carcinogeninduced DNA damage and repair enzymes in rats. Cancer Lett., 109, 185-191.

Wieslander, G., Norbäck, D., Wang, Z.H., Zhang, Z., Yahong, M. \& Lin, R.F. (2000) Buckwheat allergy and reports on asthma and atopic disorders in Taiyuan City, Northern China. Asian Pac. J. Allergy Immunol., 18, 147-152. 